\title{
Analysis of prescriptions dispensed at community pharmacies in Nablus, Palestine
}

\author{
A.F. Sawalha, ${ }^{1,2}$ W.M. Sweileh, ${ }^{2}$ S.H. Zyoud, ${ }^{1}$ S.W. Al-Jabi, ${ }^{2}$ F.F. Bni Shamseh ${ }^{7}$ and A.A. Odah ${ }^{7}$
}

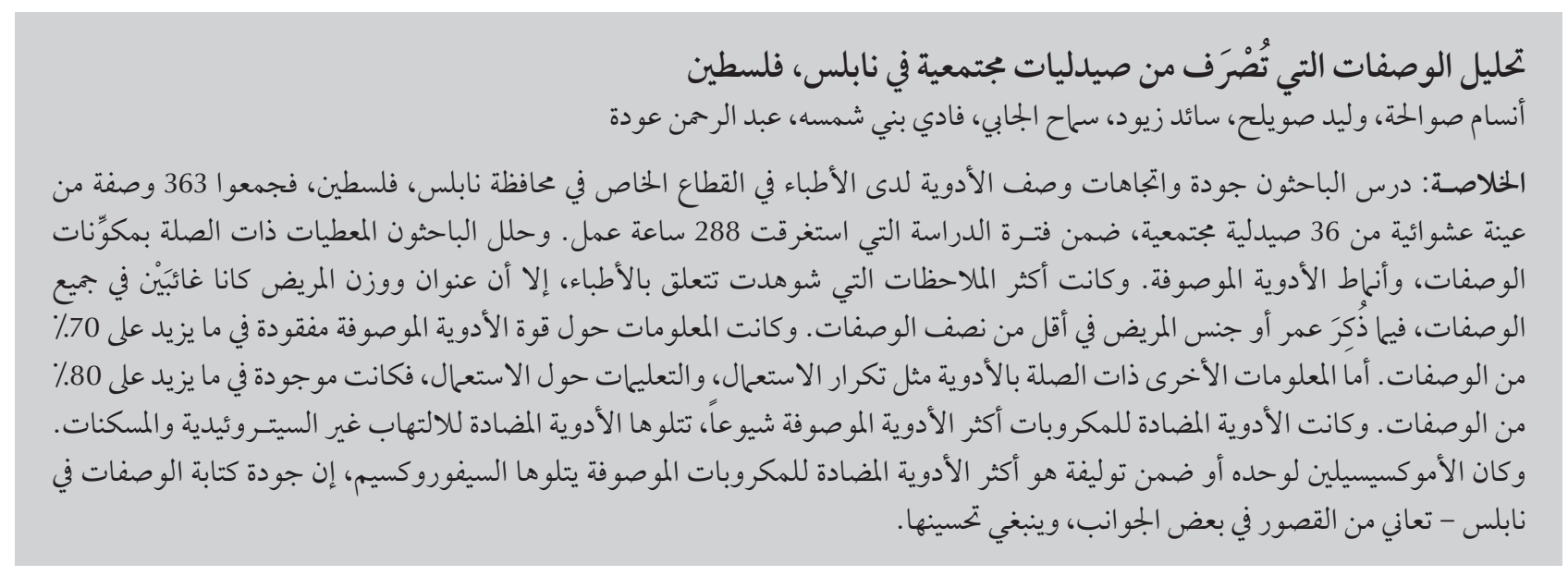

ABSTRACT We investigated the prescription quality and prescribing trends of private clinicians in Nablus governorate, Palestine. A total of 363 prescriptions were collected from a random sample of 36 community pharmacies over a study period of 288 working hours. Data regarding elements in the prescription and the types of drugs prescribed were analysed. Physician-related variables were mostly noted, however, patient's address and weight were absent in all prescriptions and less than half included age and sex. Information regarding strength of the medications prescribed was missing in over $70 \%$ of prescriptions. Other drug-related variables like frequency and instruction of use were present in over $80 \%$ of prescriptions. Antimicrobial agents were the most commonly prescribed followed by NSAIDs/analgesics. Amoxicillin alone or in combination was the most commonly prescribed antimicrobial agents followed by cefuroxime. Prescription writing quality in Nablus is deficient in certain aspects and improvement is required.

\section{Analyse des prescriptions délivrées dans des pharmacies communautaires de Naplouse (Palestine)}

RÉSUMÉ Nous avons étudié la qualité et les tendances de prescription de cliniciens privés du gouvernorat de Naplouse (Palestine). Au total, 363 ordonnances ont été collectées auprès d'un échantillon aléatoire de 36 pharmacies communautaires, au cours d'une période d'étude de 288 heures ouvrables. L'analyse a porté sur les informations relatives aux éléments figurant sur l'ordonnance et sur les types de médicaments prescrits. Les données concernant le médecin étaient indiquées dans la plupart des cas, mais moins de la moitié des ordonnances comportaient l'âge et le sexe du patient et aucune d'entre elles ne précisait son adresse ni son poids. Les informations relatives au dosage des médicaments prescrits manquaient sur $70 \%$ des ordonnances. D'autres variables, notamment la fréquence et le mode de prise, figuraient sur plus de $80 \%$ des ordonnances. Les médicaments les plus souvent prescrits étaient les agents antimicrobiens, suivis des médicaments antiinflammatoires non stéroïdiens/analgésiques. Parmi les agents antimicrobiens, l'amoxicilline seule ou en association était la plus fréquemment prescrite, suivie du céfuroxime. La qualité de rédaction des prescriptions délivrées à Naplouse est défaillante sur certains points et une amélioration est nécessaire. 


\section{Introduction}

Once a patient with a clinical problem has been evaluated and a diagnosis has been reached, the practitioner usually selects a drug therapy regimen from a variety of therapeutic approaches. This requires the writing of a prescriptionusually for medication. Prescription writing is not merely putting a few drug names on a piece of paper, rather it is an art which can be attained only after years of experience, hard work and sound knowledge of the basic subject.

Although different countries might have slightly different formats, all prescriptions need to include the following basic elements: name, address, specialty and signature of the prescriber as well as the name, sex, and age of the patient and the strength, quantity, dose, frequency, dosage form and instructions for use of the medication [1-4]. Adherence by the physician to good quality prescribing will minimize errors and ultimately improve patient care. Prescribing errors can occur as a result of errors in decisionmaking or the prescription-writing process. Unfortunately, incorrect prescribing habits are not uncommon $[5,6]$.

The purpose of this study was to screen drug prescriptions dispensed at community pharmacies in the $\mathrm{Na}$ blus area in Palestine for the essential elements of prescriptions mentioned above, and to investigate the prescribing trends of drugs dispensed at community pharmacies. The results of this study may be used by health officials to optimize drug prescribing practices and improve the patient's pharmaceutical care.

\section{Methods}

All 150 community pharmacies in $\mathrm{Na}$ blus governorate were stratified into 6 subdistricts. A random sample of 5 or more pharmacies was selected from each sub-district, according to the number of pharmacies in the sub-district and according to the willingness of the community pharmacist to participate in the study. There were no refusals to participate, so the response rate was $100 \%$ and a total of 36 pharmacies were surveyed.

We collected prescriptions written by private specialists, general practitioners and physicians at private medical centres. Prescriptions were collected from the selected community pharmacies on the same day. Collection was carried out by 36 senior pharmacy students. Each student was randomly assigned to a community pharmacy and was asked to collect all dispensed prescriptions on the study day. Information present on the prescription was transferred to a special for further analysis. The prescriptions were carefully analysed for physician, patient and drug indicators using a checklist for the items listed above. Types of drugs prescribed were analysed to determine the most commonly prescribed drug classes. All data in prescriptions were entered in the form by the first 3 authors and were checked by the rest of the authors. All data were entered and analysed using SPSS, version 16.0. Data were recorded using a 0 or 1 coding system. For each variable, a score of 1 was entered when the variable was present and compliant with the standard.

Physicians in the area did not know about the study but the university ethics committee and pharmaceutical bodies gave approval.

\section{Results}

A total of 367 prescriptions were collected during a study period of 288 work hours ( 36 pharmacies $\times 8$ hrs). All were private prescriptions. Only brand names were used on the prescriptions. The number of drugs prescribed ranged between 1 and 6, and 91.8\% of prescriptions included 3 or fewer drugs. A total of 752 medications were present in the 367 prescriptions, with an average of 2.0 per prescription (Figure 1).

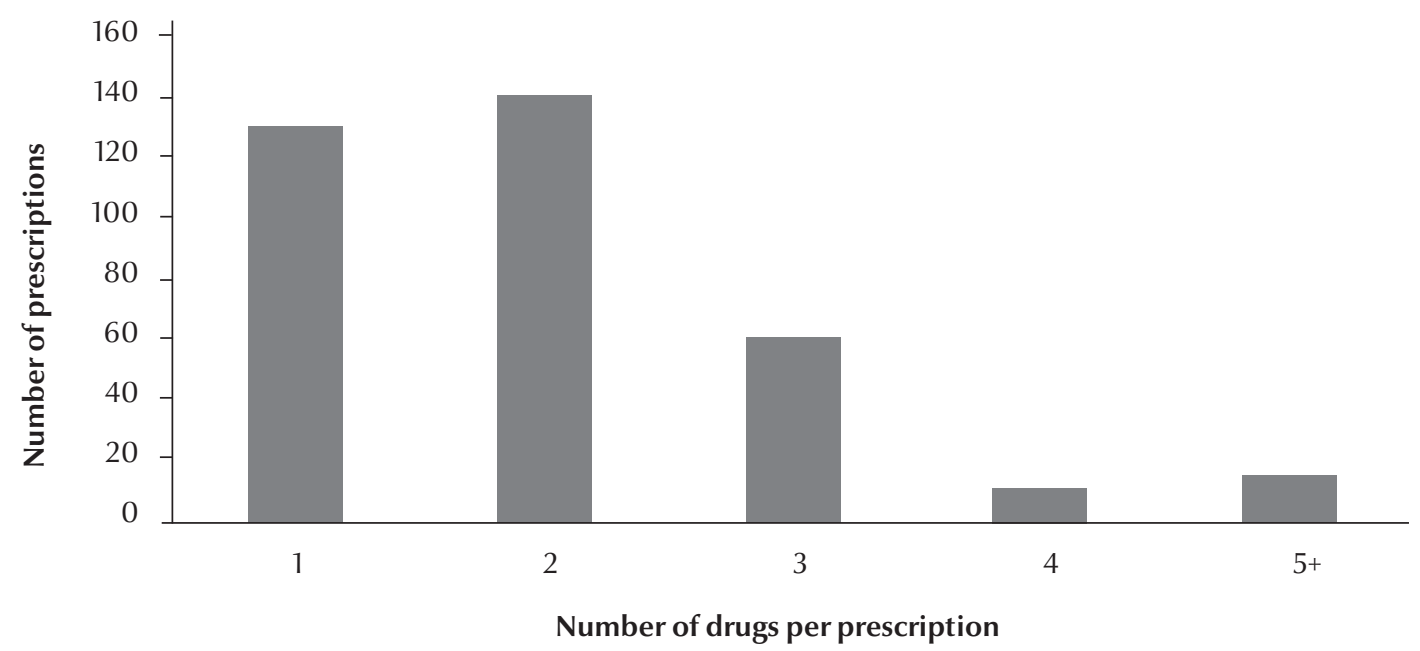

Figure 1 Number of drug items present in the prescriptions dispensed at the community pharmacies 


\begin{tabular}{lcc}
\hline $\begin{array}{l}\text { Table 1 Analysis of prescriber and patient information present on prescriptions } \\
(\boldsymbol{n}=\text { 367) }\end{array}$ & No. \\
\hline Information present & 525 & \\
Physician-related & 316 & 88.6 \\
$\quad$ Address & 315 & 86.1 \\
Specialization & 298 & 85.8 \\
Signature & 203 & 81.2 \\
Date & 0 & 55.3 \\
Drug numbering & & 0.0 \\
License number & 335 & \\
Patient-related & 128 & 91.3 \\
Name & 93 & 34.9 \\
Age & 0 & 25.3 \\
Sex & 0 & 0.0 \\
Weight & 0.0 \\
Address & & 0.3 \\
\hline
\end{tabular}

The majority of the prescriptions contained the date of the prescription, address, specialty and signature of the prescriber and name of the patient (Table 1). None of the prescriptions included the weight or address of the patient.

Drug-related variables were also analysed (Table 2). Strength of medication was indicated for all drugs in $27.8 \%$ of the prescriptions and for some drugs in $23.7 \%$. However, in about half the prescriptions, the strength of medication was missing for all drugs. The total quantity of a drug to be dispensed was not indicated for any drug in just over $25 \%$ of prescriptions. The instructions for taking the medication were complete in only $82.3 \%$ of prescriptions (Table 2).
A total of 172 prescriptions containing antimicrobial agents were dispensed during the observation period, accounting for $46.9 \%$ of all prescriptions (Table 3); 26 (7.1\%) included $>1$ agent. Amoxicillin alone or in combination (39.0\%) was the most commonly prescribed antibiotic, followed by cefuroxime $(9.9 \%)$ (Table 4). There were 147 (40\%) prescriptions containing non-steroidal anti-inflammatory drugs (NSAIDs) and/or analgesics. Of these, $12(8.2 \%)$ included $>2$ NSAIDs. The most common drug prescribed in this category was diclofenac sodium. Vitamin preparations accounted for $11.2 \%$ of all drugs dispensed (see Table 3 for details)

It was noted that 9 (2.5\%) prescriptions were for dipyrone, which is not approved for use in many countries.

\section{Discussion}

This was the first study to investigate the quality of prescription writing and the prescribing trends in community pharmacies in Palestine. The study clearly showed that there are some deficiencies in the quality of prescription writing. None of the prescriptions contained the address of the patients and less than half included the patients' age or sex. These elements should be included according to World Health Organization [1]. Other studies carried out in other developing countries have shown similar, less than optimal prescription quality. A study of outpatient prescriptions kept by the pharmacy department at Asir Central Hospital in Saudi Arabia showed that prescriptionswere deficient [7]. Another Saudi Arabian study of prescriptions from 22 general hospitals showed that documentation was not generally complete [8]. A study in Sudan also found that the quality of drug prescribing among hospital doctors had serious deficiencies in comparison with studies done elsewhere [9].

One of the problems encountered in the analysis of prescriptions was that physicians paid little attention to the strength of prescribed drugs and to the total quantity of each drug to be dispensed. Such deficiencies might create confusion for the dispensing pharmacist and given the poor pharmacist-physician communication the patient might receive the wrong strength or sub optimum quantities of the drug. Moreover,

\begin{tabular}{|c|c|c|c|c|c|c|}
\hline \multirow[t]{2}{*}{ Variable } & \multicolumn{2}{|c|}{$\begin{array}{l}\text { Included for all drugs in } \\
\text { prescription }\end{array}$} & \multicolumn{2}{|c|}{$\begin{array}{l}\text { Included for some drugs in } \\
\text { prescription }\end{array}$} & \multicolumn{2}{|c|}{$\begin{array}{l}\text { Not included for any drug in } \\
\text { prescription }\end{array}$} \\
\hline & No. & $\%$ & No. & $\%$ & No. & $\%$ \\
\hline Frequency & 343 & 93.5 & 12 & 3.2 & 12 & 3.3 \\
\hline Quantity per dose & 330 & 89.9 & 15 & 4.1 & 22 & 6.0 \\
\hline Dosage form & 325 & 88.6 & 21 & 5.7 & 21 & 5.7 \\
\hline Instructions for use & 302 & 82.3 & 21 & 5.7 & 44 & 12.0 \\
\hline Total quantity to be dispensed & 225 & 61.3 & 40 & 10.9 & 102 & 27.8 \\
\hline Strength & 108 & 27.8 & 81 & 23.7 & 178 & 48.5 \\
\hline
\end{tabular}




\begin{tabular}{lcc}
\hline $\begin{array}{l}\text { Table } 3 \text { Prescribing trends of various drug classes dispensed at community } \\
\text { pharmacies }\end{array}$ & No \\
\hline Drug class & 172 & $\%$ \\
Antimicrobials & 147 & 46.9 \\
NSAIDs/analgesics & 48 & 40.0 \\
Dermatological preparations & 41 & 13.1 \\
Vitamins & 37 & 11.2 \\
Gastrointestinal medications & 37 & 10.0 \\
Antihistamines & 26 & 10.0 \\
Mental drugs & 26 & 7.0 \\
Ophthalmics & 26 & 7.0 \\
Cough syrups & 26 & 7.0 \\
Bronchodilators & 18 & 7.0 \\
Corticosteroids & 37 & 5.0 \\
Others & & 10.1 \\
\hline
\end{tabular}

Each prescription might contain several different drug classes and therefore the sum of percentages exceeds $100 \%$. NSAID = non-steroidal anti-inflammatory drug.

a number of the prescriptions had inadequate information on instruction for use, which might lead to poor compliance. Only brand names of the medications were used in the prescriptions. This might impose dispensing problems for the pharmacists since not all community pharmacies can afford to store the wide variety of brand names of the same drug. The lack of generic prescribing in this

study is different from prescription practices in some other developing countries: Uzbekistan 38\%, Cambodia 99.8\% and India 46\% [10-12]. There are no regulations on generic prescribing in Palestine. Therefore, generic prescribing should be actively promoted to facilitate rational and cost-effective prescribing practices.

As is typical in developing countries, anti-infective agents, analgesics

\begin{tabular}{lcc}
\hline Table 4 Review of prescriptions containing antimicrobial agents $(\boldsymbol{n}=\mathbf{1 7 2})$ \\
\hline Drug class & No. & $\%$ \\
Fluoroquinolones & 11 & 6.4 \\
$\quad$ Ciprofloxacin & 4 & 2.3 \\
$\quad$ Ofloxacin & & \\
Macrolides & 16 & 5.9 \\
Azithromycin & 7 & 4.1 \\
Clarithromycin & 4 & 2.3 \\
Erythromycin & & \\
Amoxicillin & 31 & 18.0 \\
Amoxicillin + clavulanic acid & 29 & 16.9 \\
Amoxicillin & 7 & 4.1 \\
Amoxicillin + cloxacillin & & \\
Cephalosporins & 17 & 9.9 \\
Cefuroxime & 10 & 5.8 \\
Metronidazole & 8 & 4.7 \\
Cefadoxil & 5 & 2.8 \\
Cephalexin & 3 & 1.7 \\
Sulfamethoxazole + trimethoprim & 20 & 11.6 \\
Other & &
\end{tabular}

and vitamin supplements constituted a high proportion of drugs dispensed, whilst medications for cardiovascular diseases and mental health problems were less frequently dispensed [12-14]. A probable reason for over-prescribing of antibiotics is, as reported in other countries, the high prevalence of infection $[11,12,15-18]$. Over-prescribing was evident particularly for children and in cases where the infection was of likely viral origin. Newer generation antibiotic (coamoxiclav, azithromycin, and ciprofloxacin) use was relatively high, adding to costs and potentially affecting resistance patterns $[19,20]$. Given the current high levels of unemployment (26\%) and poverty $(67 \%)$ in Palestine, medicine costs present a significant financial burden to patients $[21,22]$. Unfortunately, no data on microbial resistance for the most commonly prescribed antibiotics studied are available in Palestine to facilitate developing evidence-based antibiotic prescription guidelines.

Analgesics and NSAIDs were commonly prescribed but less than that in neighbouring countries such as Saudi Arabia (51\%) and the Islamic Republic of Iran (63\%) [16,23]. Analgesics such as dipyrone continue to be marketed and prescribed. In many parts of the world, dipyrone is considered a dangerous drug and is banned. Serious adverse effects, often leading to fatalities, were observed and confirmed over 60 years ago $[24,25]$. The Palestinian Ministry of Health needs to revise the registration status of dipyrone for analgesic use based on current data. Furthermore, prescribers need to be aware of the toxic effects of dipyrone.

This study is limited in that only community pharmacies in Nablus district were included. Another limitation is that the prescription collection was made on only 1 working day rather than over a long period. Despite these limitations, there was evidence of suboptimal prescribing practices with overprescribing of certain drug categories, particularly new generation antibiotics. 


\section{References}

1. De Vries TP et al., eds. Guide to good prescribing: a practical manual. Geneva, World Health Organization, 1995:51-55 (WHO/DAP/94.11).

2. Lofholm PW, Katzung BG. Rational prescribing and prescription writing. In: Katzung BG, ed. Basic and clinical pharmacology, 8th ed. New York, McGraw-Hill, 2001:1104-1112.

3. Prescription writing. In: British national formulary, No. 41 London, British Medical Association \& Royal Pharmaceutical Society of Great Britain, 2000:4-5.

4. Safe writing. In: Lacy CF et al., eds. Drug information handbook, 9th ed. Cleveland, Ohio, Lexi-Comp, 2001:12.

5. Blatt $A$, Chamban $R$, Lemardeley P. Forme lègale et coût des prescriptions à I'Hôpital Central de Yaoundé, Cameroun [Legal format and costs of prescriptions at the Central Hospital in Yaounde, Cameroon]. Médecine Tropicale, 1997, 57(1):37-40.

6. François $\mathrm{P}$ et al. Evaluation of prescription-writing quality in a French university hospital. Clinical Performance and Quality Health Care, 1997, 5(3):111-115.

7. Irshaid YM et al. Compliance with good practice in prescription writing at outpatient clinics in Saudi Arabia. Eastern Mediterranean Health Journal, 2005, 11(5-6):922-928.

8. Bawazir S. Prescribing pattern of ambulatory care physicians in Saudi Arabia. Annals of Saudi Medicine, 1993, 13(2):172-177.

9. Yousif E et al. Deficiencies in medical prescriptions in a Sudanese hospital. Eastern Mediterranean Health Journal, 2006,12(6):915-918.

10. Pavin $\mathrm{M}$ et al. Prescribing practices of rural primary healthcare physicians in Uzbekistan. Tropical Medicine \& International Health, 2003, 8(2):182-190.

11. Chareonkul C, Khun VL, Boonshuyar C. Rational drug use in Cambodia: study of three pilot health centers in Kampong Thom Province. Southeast Asian Journal of Tropical Medicine \& Public Health, 2002, 33(2):418-424.

12. Hazra A, Tripathi SK, Alam MS. Prescribing and dispensing activities at the health facilities of a non-governmental organisation. National Medical Journal of India, 2000, 13(4):177-182.
13. The world drug situation. Geneva, World Health Organization, 2004.

14. Karande S, Sankhe P, Kulkarni M. Patterns of prescription and drug dispensing. Indian Journal of Pediatrics, 2005, 72(2):117121

15. Otoom $\mathrm{S}$ et al. Evaluation of drug use in Jordan using WHO prescribing indicators. Eastern Mediterranean Health Journal. 2002, 8(4-5): 537-543.

16. Moghadamnia AA, Mirbolooki MR, Aghili MB. General practitioner prescribing patterns in Babol city, Islamic Republic of Iran. Eastern Mediterranean Health Journal, 2002, 8(4-5): 550-555.

17. Nsimba SE, Massele AY, Makonomalonja J. Assessing prescribing practices in church-owned primary healthcare $(\mathrm{PHC})$ institution in Tanzania: a pilot study. Tropical Doctor, 2004, 34(4):236-238.

18. McCaig LF, Besser R, Hughes M. Trends in antimicrobial prescribing rates for children and adolescents. Journal of the American Medical Association, 2002, 287(23):3096-3102.

19. Stimac D, Vukusic I, Culig F. Outpatient use of systemic antibiotic in Croatia. Pharmacy World and Science, 2005, 27(3):230235.

20. Priest $\mathrm{P}$ et al. Antibiotic prescribing and antibacterial resistance in English general practice: cross sectional study. British Medical Journal, 2001, 323(7320):1037-1041.

21. Palestine in numbers, 2004. Ramallah, Palestine, Palestinian Central Bureau of Statistics, 2005:17.

22. Palestine human development report, 2004. Birzeit Palestine, Development Studies Programme, Birzeit University, 2005:61.

23. Irshaid $\mathrm{Y}$ et al. A pharmacoepidemiological study of prescription pattern in outpatient clinics in South-Western Saudi Arabia. Saudi Medical Journal, 2004, 25(12):1864-1870.

24. Hugueley CM. Agranulocytosis induced by dipyrone, a hazardous antipyretic and analgesic. Journal of the American Medical Association, 1964, 189(12):938-941.

25. Simpson RG. Aminopyrine and agranulocytosis. British Medical Journal, 1963, 1(5334):877. 